\title{
THE EFFECTS OF CONSUMER-GENERATED MEDIA ON VIETNAMESE TRAVELERS' DECISION MAKING - MEDIATION ANALYSIS OF PERCEIVED CREDIBILITY AND TRUST
}

\author{
Hoang Thanh Nhon \\ International University-Viet Nam National University-HCMC \\ School of Business, International University, Quarter 6, Linh Trung \\ Ward, Thu Duc District, Ho Chi Minh City, Vietnam \\ htnhon@hcmiu.edu.vn \\ Mai Ngoc Khuong \\ International University-Viet Nam University-HCMC \\ School of Business, International University, Quarter 6, Linh Trung \\ Ward, Thu Duc District, Ho Chi Minh City, Vietnam \\ mnkhuong@hcmiu.edu.vn
}

\begin{abstract}
This study investigates the factors influencing consumer perception of credibility of online travel-related information on online communities, especially on online social networks and, in turn, the degree to which the perception of online information credibility affects trust and travel decision making. Online and offline surveys of Vietnamese consumers were conducted with a total of 328 individuals responding to questionnaires regarding the determinants of consumer perceptions, online trust and the use of online information for travel decisions. The findings show that online social network use is widespread in travel information exchanges and the degree of perception of online information credibility by the consumer has a positive effect on trust, as well as on the travel decision of the consumer.
\end{abstract}

Keywords: Consumer-Generated Media, Perceived Credibility, Travel Decision Making, Trust and Social Network 


\section{INTRODUCTION}

Tourism is an information-intensive industry ${ }^{1}$. Therefore, travelers usually pay attention to the activity of information search to satisfy their information needs. Pan and Fesenmaier ${ }^{2}$ listed nine key concerns regarding travel planning, namely: travel partners, destination, trip budget, activities, travel dates, places visited, transportation providers, trip length and food. Fesenmaier and Jeng ${ }^{3}$ found that travelers generally search for online travel-related information in the pre-travel stage in order to minimize the risks of making an unfavorable travel decision. Web 2.0 sites such as blogs, social network sites and review sites have been emerging as the central hub for travelers to search for online travel-related information for their trip $\operatorname{plan}^{4}$. With the advent of Web 2.0 technologies, travelers today can actively collaborate with peers in creating, using and diffusing travel information through the Internet, what is called travel-related consumer-generated media. Consumer-generated media (CGM) becomes an important online information source for travelers in the context of travel decision-making 5, 6 . In America, CGM is especially important since trip planners often rely on others' experiences for their travel decision-making. Indeed, a study reported that more than 80 percent of American travel product purchasers were influenced by various types of travel-related CGM including videos, reviews, blogs, social networking media comments or other online forms of feedback in the context of a travel purchase intention ${ }^{7}$. Meanwhile, in Vietnam, travel information search related to CGM use is not the most popular online activity. According to a study of Vina Research, a Vietnamese market researcher, more than 70 percent of surveyed Vietnamese travelers responded that they gather travel information from friends, family members and travel agencies, while only about 14.4 percent look up information from online tourism communities and social network sites $^{8}$. However, the 89.2 percent of Vietnamese travelers who are younger than 30 years old said that they are interested in online sharing activities such as posting photographs, video and commenting on tourism services in the post-travel stage ${ }^{8}$. Therefore, it is predicted that travel-related CGM will be preferred and become an influential source for travel decision making in the near future.

Even so, there are increasing numbers of online travelers who use GCM, especially Facebook or backpacker forums, for sharing, discussing and exchanging their trip experiences, CGM is often perceived as less trustworthy than traditional tourism information channels. The study of Smith, Menon \& Sivakumar ${ }^{9}$ indicated that the information credibility issue is mostly concerned in travel-related CGM due to information source 
anonymity. In addition, the credibility is also influenced by the quality of the information and the expertise of source providers. Online information credibility is defined as the degree to which online consumers evaluate online information or posted messages on CGM to be trustworthy ${ }^{10,11}$ Evaluating the credibility of a CGM source is more difficult than evaluating information from traditional channels due to the weak quality control mechanism of the third party in the online environment ${ }^{12}$. Johnson \& Kaye ${ }^{11}$ indicated that consumers or Internet users are usually free to upload information without any confirmation process to ensure the quality of information. Therefore, the absence of any filtering mechanism may result in inaccurate or false information being released in Web-based media. In addition, CGM or other Internet sources offer interactive characteristics with which consumers may replicate, duplicate, manipulate and disseminate information easily ${ }^{13}$. As a result, inaccurate information may be reproduced by recipients with extraordinary simplicity. Therefore, the uncertainty about the credibility of online information is a key point, which will be investigated further in this research. Most research on the subject has examined perceiving credibility of online travel community or travel-related CGM as well as the influence of credibility perception on the traveler's trust in making travel decisions in developed countries, especially in America. In Vietnam, these issues above are quite new and have not been discussed. Therefore, this study will focus on discussing these issues. Furthermore, we continue to examine the factors that drive online credibility perception in travel-related CGM on social network sites and domestic tourism forums.

\section{THEORETICAL BACKGROUND AND HYPOTHESIS DEVELOPMENTS}

\subsection{Uncertainty Reduction Theory}

The Uncertainty Reduction Theory is used as the key theory in this study. The Uncertainty Reduction Theory was originally developed to explain the dynamics of human communication ${ }^{14}$. The Uncertainty concept in communication is defined as an individual's inability to predict other people's behavior ${ }^{15}$. The important assumption of this theory is that an increase of behavior predicting ability in human interaction is the primary key in reducing uncertainty in communication, as well as enhancing the degree of information credibility in communication ${ }^{14}$. Therefore, a high level of uncertainty in initial interactions motivates parties to engage in information-seeking activities, such as behavior observation and conversation participation, by which the level of liking, intimacy and similarity among them may be develope ${ }^{16,17}$. The Internet-mediated communication refers to the facilitation of sophisticated interactions among 
individuals, both synchronous and asynchronous by virtue of IT devices ${ }^{18}$. Compared to face-to-face communication, the participants in online communication are limited in observing and evaluating the attitudes or behavior of partners ${ }^{19}$. This problem is aggravated by anonymity. Therefore, in this study, we focused on finding out how to reduce uncertainty in information sources. In other words, we emphasize what the factors that enhance the degree of information credibility in CGM are.

\subsection{Trust Definition}

Based on the trust concept of Moorman ${ }^{20}$, in this study, trust is defined as the positive expectation of tourism products or services, without having prior experience of those two aspects, after a consumer's awareness is exposed to product information, which is likely to be perceived as credible. A consumer's preferences and decisions about tourism services depend on the perception of travel-related information credibility. Therefore, when information is perceived as credible, trust in the product will be formed, and then the travel service or product purchase intention will also be developed $^{21}$. Information credibility perception is a central element in the decision-making process through its effect on a consumer's degree of trust and behavioral intentions. Hence, hypotheses are developed as follows:

H1: Perceiving information credibility positively affects trust.

$\mathrm{H}$ 2: Perceiving information credibility positively affects travel decision making.

H3: Trust positively affects travel decision making.

\subsection{Factors Affecting Perceiving Information Credibility and Trust}

Parks and Floyd ${ }^{22}$ argued that raising the ability of predicting source identity, understanding personality (Openness), perceiving similarity and Internet expertise of the online communication partners will significantly enhance the online credibility perception of consumers.

\subsubsection{Internet Experience}

The Internet experience of online consumers refers to familiarity with websites, online skills and online entertainment experiences in Internet usage. Johnson and $\mathrm{Kaye}^{23}$ suggest that online credibility perception is influenced by Internet expertise. It is found that the more people use the Internet, the more they will judge that online information is credible. In addition, Greer ${ }^{24}$ also claims that the amount of time spent on Internet use is 
the strongest predictor of whether the online media would be considered as credible. Drawing upon findings from previous research, this study suggests that individuals with a high level of Internet experience are likely to perceive greater credibility on Consumer-Generated Media information and have a higher degree of trust than individuals with less experience. Therefore, the following hypotheses are proposed:

H4a: Perceiving information credibility is positively affected by internet experience.

$\mathrm{H} 4 \mathrm{~b}$ : Trust is positively affected by internet experience.

H4c: Travel decision making is positively affected by internet experience.

\subsubsection{Openness}

In tourism research, personality has often been used as a basis for market segmentation purposes. A number of tourism studies suggest that personality is related to travel destination choices, leisure activities and other travel-related decisions ${ }^{25,26}$. Another study of Turten and Bosnjak ${ }^{27}$ found that openness, a factor of personality, described by adjectives like imaginative, curious, broad-minded and intelligent, is positively related to the degree of perceiving and trusting online entertainment and travel information. Therefore, this study suggests that individuals with a high level of openness would perceive greater credibility and trust of Consumer-Generated Media information than individuals with a low level of openness. The following hypothesis is proposed:

H5a: Perceiving information credibility is positively influenced by openness.

H5b: Trust is positively influenced by openness.

H5c: Travel decision making is positively influenced by openness.

\subsubsection{Source Identity}

$\mathrm{Ma}$ and $\mathrm{Agarwal}^{28}$ defined source identity as the following: "Source Identity in online communication refers to the extent to which Consumer-Generated Media information discloses the basic personal information about the identity or personal details of the individuals who posted the reviews."

The findings of the study of Susan and Seigal $^{29}$ indicated that information acquisition is more efficient when the source is identifiable, and an identifiable source enhances the information trustworthiness, and so the identified sources are likely to be deemed credible and useful. Therefore, the following hypotheses are proposed: 
H6a: Source identity positively affects perceiving information credibility.

H6b: Source identity positively affects trust.

H6c: Source identity positively affects travel decision making.

\subsubsection{Similarity}

In the online environment, perceived similarity refers to the extent to which a consumer feels similar to the sender who posts online a review or comments on Consumer-Generated Media in terms of attitudes, preferences, emotions and behaviors ${ }^{9}$. Online consumers with similar social, demographic and psychographic characteristics tend to have similar needs and trust than would be expected among dissimilar individuals. Therefore, two hypotheses are developed as follows:

H7a: Similarity positively affects perceiving information credibility.

H7b: Similarity positively affects trust.

H7c: Similarity positively affects travel decision making.

\subsection{Research Model}

From the literature reviews, theoretical backgrounds and hypothesis development, a conceptual framework for credibility of Consumer-Generated Media information is developed as following:

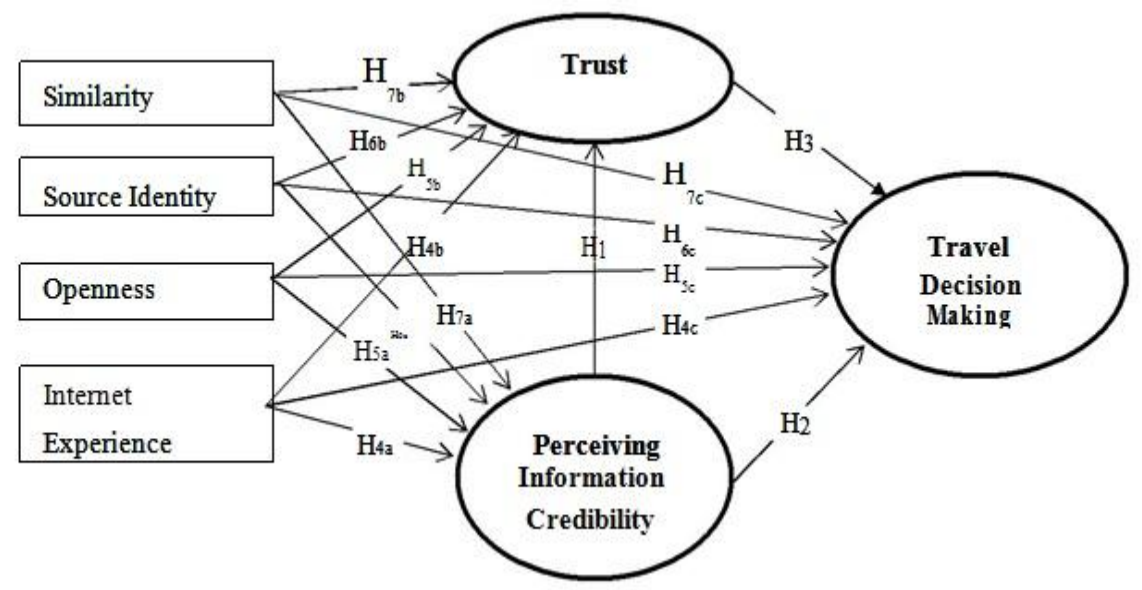

Figure 1. Conceptual model 


\section{RESEARCH METHODOLOGY}

\subsection{Data Collection and Sampling}

Our study targets members of Facebook, Twitter and online domestic travel communities. We distributed 500 questionnaires to students, professional staff, business owners and others, and also conducted an online survey on Facebook, Twitter and online domestic travel communities from the beginning of February, 2014 to the middle of March, 2014. Eventually, 328 responses were collected, of which 47.6 percent and 52.4 percent were males and females, respectively. With regard to occupational level, the largest number of respondents were professional staff comprising 71 percent of the survey sample, while the second largest number were students, accounting for only 16.5 percent. Demographic information also indicated that 16.8 percent of the respondents were between 19 and 22 years old, 30.8 percent between 23 and 30 years old, 30.8 percent between 30 and 35 years old and 16.2 percent were older than 35 . Therefore, the major participants in our survey were younger than 35 years old ( 83.8 percent). In addition, of the sample, 100 percent answered that they use Facebook as an online communication channel to exchange and search travel-related information, 13.7 percent use both Facebook and an online tourism forum to look up tourism information, while only 9.1 percent use all three online communities (Facebook, Twitter and an online tourism forum) to look up tourism information.

\subsection{Measurement Developments}

Firstly, we developed questionnaire items to measure each of the constructs in the research model, adapted from prior literature, and each item was measured on a 5-point Likert scale, ranging from 1: Strongly disagree, 2: Disagree, 3: Neutral, 4: Agree and 5: Strongly agree. The scale for Travel Decision Making variables, based on the purchase intention concept, was adapted from Dodds et $\mathrm{al}^{30}$. The Online Trust scale used in this study was developed by Bart et $\mathrm{al}^{31}$. to measure Trust determinants, and the scale for perceiving the credibility of online information measured by accuracy, believability, lack of bias and completeness factor, was adapted from Flanagin \& Metzger ${ }^{10}$, which was originally developed by West ${ }^{32}$. In addition, Flanagin \& Metzger ${ }^{10}$ use four indicators, namely: Internet use, experience, expertise and access to develop the measurement scale for internet experience. Items to measure openness, source identity and similarity developed are based on the work of Barrick and Mount ${ }^{33}$.

Secondly, to evaluate the dimensionality and reliability of the measurement scales, we used factor analyses and Cronbach's alpha $(\alpha)$, 
respectively. We conduct factor analyses for all measurement items of constructs to analyze the dimensionality of scale. The condition for uni-dimensionality confirmation is that factor loading value of every item should be above the recommended level of $0.5^{34}$. Subsequently, we use $\alpha$ for reliability analysis in order to measure the internal consistency of the measurement scales. The acceptable value of $\alpha$ should be above 0.6.

Finally, we applied an indirect effect measurement method. In prior researches, when researchers test the structural model, they often focus only on direct relationship measurement among constructs, thus, to strengthen the causal effect relationship measurement among constructs, we performed indirect effect test. Indirect effect measurement involves in testing how an independent variable $(\mathrm{X})$ affects a dependent variable $(\mathrm{Y})$ through one or more potential intervening variables or mediators $[\mathrm{M}(\mathrm{s})]^{35}$. Hayes ${ }^{35}$ defined a method to test the indirect effect, called Bootstrapping method, as the following:

"Bootstrapping is computation-ally intensive method that involves repeatedly sampling from data set and estimating the indirect effect in each resampled data set. By repeating this process thousands of times, an empirical approximation of the sampling distribution of product of $a$ and $b$ ( $a$ and $b$ values are unstandardized coefficient value of $X->M, M->Y$, respectively) is built and used to construct confident intervals for indirect effect. If zero is contained in the interval, there is no indirect effect of $X$ to $Y$ through M."

Therefore, in this study, we used the Bootstrapping method to test the significance of the indirect effects of internet experience, openness, source identity and similarity to travel decision making through two mediators of trust and perceiving information credibility, respectively.

\section{RESULTS}

\subsection{Result of the Reliability and Dimensionality Evaluation}

The result of reliability and dimensionality test shows that the Cronbach's alpha $(\alpha)$ of source identity, similarity, openness, internet experience, trust and travel decision making constructs satisfied value of 0.6 recommended by Nunnally $^{36}$, while $\alpha$ of openness and perceiving information credibility close to 0.6 . Therefore, scores of the $\alpha$ indicated that the conceptual model is reliable for measuring items of each construct. In addition, for dimensionality analysis, all factor loading scores are above the suggested level of $0.5^{34}$, so the results of this analysis satisfied the condition of uni-dimensionality confirmation. 


\subsection{Correlation Matrix}

The test result of correlation matrix indicated that all independent variables (openness, source identity, similarity and internet experience) had significant correlation with dependent variables (perceiving information credibility, trust and travel decision making). Among independent variables, internet experience had strongest correlation with perceiving information credibility $(r=0.351, p<0.01)$ and travel decision making $(r=0.352, p<$ $0.01)$. In other words, the consumers who had higher level of internet experience may shorten the process of perceiving information credibility to make faster travel decision. Similarly, source identity was also strongly correlated with trust $(r=0.329, p<0.01)$ and travel decision making $(r=$ $0.327, p<0.01$ ), thus, the consumer would trust more on information sent by who have transparent profile than ones are anonymous. Among dependent variables, perceiving information credibility had strong correlations with both travel decision making $(r=0.523, p<0.01)$ and $\mathrm{t}(r=$ $0.394, p<0.01)$. In other words, online credibility perception positively affected the information trust and the development of travel decision making.

\subsection{Result of Direct Effect Measurement}

Figure 2, in below, displays the results of the structural model test with unstandardized patch coefficients between constructs where significant paths $(\mathrm{p}<0.05)$ are represented as solid lines and non-significant paths are represented as dotted lines. To measure the unstandardized coefficient weight of connected paths within research model, we conducted three multiple regression analyses. The results of all multiple regression tests displayed in Figure 2 indicated that $S$ variable was not a significant predictor of perceiving information credibility and travel decision making (H7a and H7c were not supported). Similarly, the effect of openness on trust, the effect of source identity on travel decision making and the effect of internet experience on trust were not significant $(\mathrm{H} 5 \mathrm{~b}, \mathrm{H} 6 \mathrm{c}$ and $\mathrm{H} 4 \mathrm{~b}$ were not supported). Among independent variables, internet experience was the most powerful predictor of perceiving information credibility with highest unstandardized coefficient of 0.258 . Therefore, internet experience is likely to be the most important determinant of the process of online credibility perception. In other words, if consumers do not have strong internet skills, they are not skillful enough to look up similarity with online partners to assess the trustworthiness of source identity and to make travel decision as a whole. In addition, the analyses of linear relationships between perceiving information credibility with trust and travel decision making were conducted to investigate whether online credibility perception plays a 
significant role in determining trust and travel decision making. The results presented in Figure 2 showed that consumers with higher level of perceiving information credibility are more likely to have positive effect on trust and travel decision making. However, the influence of perceiving information credibility on travel decision making is stronger than the influence of trust on travel decision making.

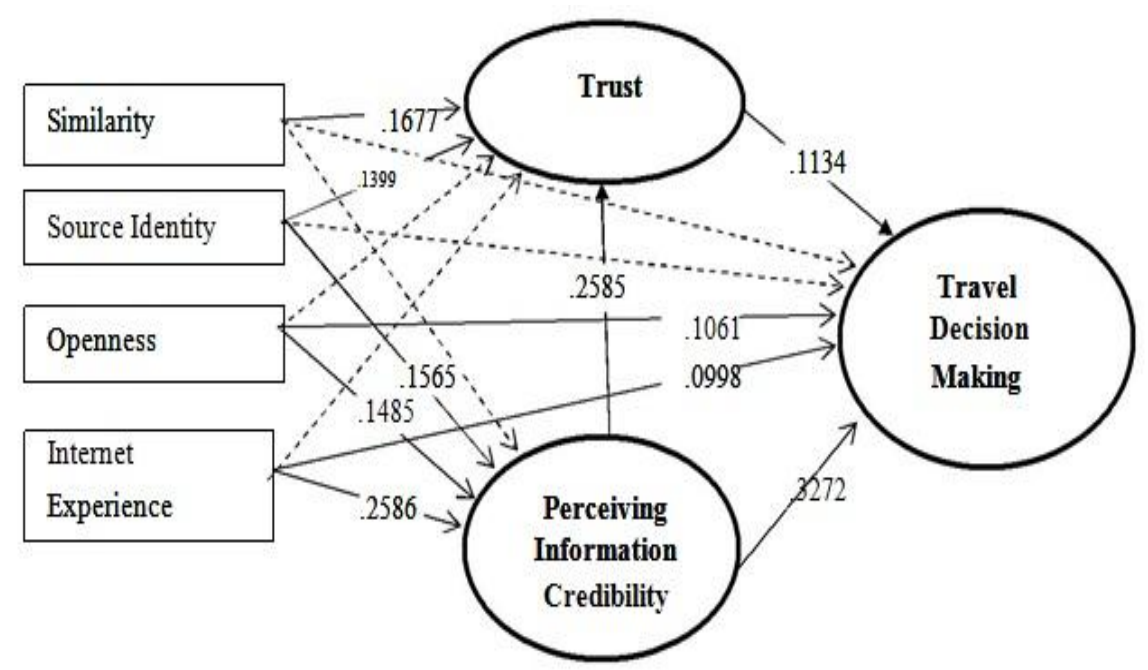

Figure 2. The test result of the conceptual model

\subsection{The Results of Indirect Measurement}

The results of the bootstrapping test recommended by Hayes ${ }^{35}$ indicated that among all variables in the research model, internet experience, openness and source identity had significant indirect effects on travel decision making through perceiving information credibility and indirect effects on travel decision making through perceiving information credibility than through trust, while similarity only had indirect influence on travel decision making through trust. In addition, among independent variables, internet experience had the largest total estimated point of indirect effect of 0.0822 and was the most influential determinants of travel decision making (internet experience had total estimated points of both indirect and direct effects of 1.0808). Moreover, all independent variables had significant indirect effect on travel decision making through perceiving information credibility with total point estimates of 0.2034 than through perceiving information credibility then trust with total point estimates of 0.0166 . Therefore, we concluded that perceiving information credibility was the most important mediator in travel decision making process. 


\section{DISCUSSION}

\subsection{Theoretical Implications}

This study investigated several research questions based on Uncertainty Reduction Theory ${ }^{14}$ to explain how customer responses to perception of travel information creditability on online social networks or tourism communities to make final travel decisions. Regarding influences of all independent variables in accessing online information credibility perception and online trust of consumer, the result of direct and indirect measurements revealed that internet experience provided the most significant influence to travel decision making directly or indirectly through perceiving information credibility and trust. In addition to internet experience, source identity was also an important indirect determinant of travel decision making through perceiving information credibility and trust. These can be explained by the fact that the stronger internet skills consumers had, the faster they perceived information credibility as well as travel decision making. Shared travel information with transparency and identified source had greater impact than with unidentified source on consumer's online credibility perception. Therefore, these explanations were consistent with the concept of Uncertainty Reduction Theory ${ }^{14}$.

\subsection{Practical Implications}

In the social network site or online community era, online consumer-to-consumer (C2C) interactions play an important role in affecting consumer decision. The online information exchanges commonly occurring in online $\mathrm{C} 2 \mathrm{C}$ interactions may generate unlimited value for all the involved stakeholders. The result of this study is important for two sets of stakeholders; namely the management of online community sites and online users.

The findings of this study indicate that consumer perception of online information creditability affects the initial trust of consumers in travel services and travel intention. In this context, there are urgent needs for developing verification or filter mechanism supporting online consumers to determine the credibility of information posted on online community sites, especially in domestic travel forums. This strategy is important for consumers who are overwhelmed by the large amount of the posted information for given travel services which confuses consumers in appropriate travel service selection. Furthermore, filter mechanism development is also important for the management of online community sites to ensure that only credible information is visible to users and eventually to enhance the credible image of sites. In Facebook, each 
travel-related, or any type of posted information, is simply evaluated by clicking on "Like" by other users, but the question raised is how serious those evaluations are. Therefore, there should be a need for further research to strengthen the filter mechanism in online sites.

\section{CONCLUSION AND LIMITATION}

In this article, we propose an integrated theoretical model to help academic researchers understand what independent variables influence the perception of the Perceiving Information Credibility and how Perceiving Information Credibility affects the Trust and Travel Decision Making. The research model was empirically evaluated using survey data collected from 328 responses. The results reveal that all independent variables directly and significantly affect the perception of the online information credibility, which affect both trust and travel decision. In addition, the implication of this study on theory and practice are also discussed above.

Although this study produces some useful and meaningful results, there are a number of limitations. First, by examining another age group variable, it may be possible to derive additional results beyond our findings here. As indicated in the profile of responses, 83.8 percent in the sample are younger than 35 years old and the study only focuses on this age group. If the study focused on those who are older than 35 years old, we may yield further insights. Second, the research model developed is based on the theoretical foundation of western literature, while the sample data was collected in Vietnam, in which cultural effects are different from those of western countries. The cultural effects are important factors in human behavior research, especially in human-computer interaction. Therefore, the practical implication part of this research may have some limitations since it has not examined the role of cultural effects on the perception of online information credibility.

Because people of different ages and cultures may react differently to information creditability perception, studying these factors may present new directions for future research. In addition, this study only focuses on the credibility issues of information exchanged between consumer and consumer. Therefore, research on the credibility of online information on business-to-customer interaction in online travel communities could be developed for further study. 


\section{REFERENCES}

[1] A. Poon, Tourism, technology, and competitive strategies. Wallingford, OX: CAB International, 1993.

[2] B. Pan, and D.R. Fesenmaier, Online information search. Annals of Tourism Research, 33(3), p809-832, 2006. http://dx.doi.org/10.1016/j.annals.2006.03.006.

[3] D.R. Fesenmaier, and J. Jeng, Assessing structure in the pleasure trip planning process. Tourism Analysis, 31(5), p13-27, 2000.

[4] K-H. Yoo, K.S. Lee, and U. Gretzel, The role of source characteristics in e-WOM: What makes online travel reviews credible and likeable? In M. Sigala, L. Mich, J. Murphy, and A. Frew (Eds.), Information and Communication Technologies in Tourism (pp. 23-24). Vienna, Austria: Springer, 2007.

[5] S.W. Litvin, R.E. Goldsmith, and B. Pan, Electronic word-of-mouth in hospitality and tourism management. Tourism Management, 29(3), p458-468, 2008. http://dx.doi.org/10.1016/j.tourman.2007.05.011.

[6] B. Pan, T. MacLaurin, and J.C. Crotts, Travel blogs and the implications for destination marketing. Journal of Travel Research, 46(1), p35-45, 2007. http://dx.doi.org/10.1177/0047287507302378.

[7] PhoCusWrightMarket Research, PhoCusWright's us online travel overview (8th Edition), 2008.

[8] Vina Research, Vina research's Vietnam online tourism overview (5th Vina Research), 2013.

[9] D. Smith, S. Menon, and K. Sivakumar, Online peer and editorial recommendations, trust, and choice in virtual markets. Journal of Interactive Marketing, 19(3), p15-37, 2005. http://dx.doi.org/10.1002/dir.20041.

[10] A.J. Flanagin, and M.J. Metzger, Perceptions of Internet information credibility. Journalism and Mass Communication Quarterly, 77(3), p515-540, 2000. http://dx.doi.org/10.1177/107769900007700304.

[11] T.J. Johnson, and B.K. Kaye, Cruising believes? Comparing Internet and traditional sources on media credibility measures. Journalism and Mass Communication Quarterly, 75(2), p325-341, 2008. http://dx.doi.org/10.1177/107769909807500208.

[12] S.Y. Reih, and D.R. Danielson, Credibility: A multidisciplinary framework. Annual Review of Information Science and Technology, 41(1), p307-364,

2007. http://dx.doi.org/10.1002/aris.2007.1440410114.

[13] AJ. Flanagin, and M.J. Metzger, The perceived credibility of the personal web page information as influenced by the sex of the source. Computer in Human Behavior, 19(6), p683-701, 2003. http://dx.doi.org/10.1016/S0747-5632(03)00021-9. 
[14] C.R. Berger, and R.J. Calabrese, Some explorations in initial interaction and beyond: Toward a developmental theory of interpersonal communication. Human Communication Research, 1(2), p99-112, 1975. http://dx.doi.org/10.1111/j.1468-2958.1975.tb00258.x.

[15] J.W. Neuliep, and E.L. Grohskopf, Uncertainty reduction and communication satisfaction during initial interaction: An initial test and replication of a new axiom. Communication Reports, 13(2), p67-77, 2000. http://dx.doi.org/10.1080/08934210009367726.

[16] C.R. Berger, Beyond initial interaction: Uncertainty, understanding, and development of interpersonal relationships. In H. Giles and R. St. Clair (Eds.), Language and social psychology (p122-144). Oxford, UK: Basil Blackwell, 1979.

[17] J.L. Gibbs, N.B. Ellison, and C.H. Lai, First come love, then comes Google: An investigation of uncertainty reduction strategies and self-disclosure in online dating. Communication Research, 38(1), p70-100, 2011. http://dx.doi.org/10.1177/0093650210377091.

[18] D. Jonassen, M. Davidson, J. Campbell, and B.B. Haag, Constructivism and computer-mediated communication in distance education. American Journal of Distance Education, 9(2), p7-26, 1995. http://dx.doi.org/10.1080/08923649509526885.

[19] M.J. Culnan, and M.L. Markus, Information technologies. In F.M Jablin, L.L. Putnam, K.H. Roberts, and L.W. Porter (Eds.), Handbook of organizational interdisciplinary perspective (p420-443). Newbury Park California: Sage Publications, 1987.

[20] C. Moorman, Factors affecting trust in market research relationships. Journal of Marketing, 57(1), p81-101, 1993. http://dx.doi.org/10.2307/1252059.

[21] P. Chen, S. Dhanasobhon, and M.D. Smith, All reviews are not created equal: The disaggregate impact of reviews and reviewers at Amazon.Com, May 2008. http://dx.doi.org/10.2139/ssrn.918083.

[22] M.R. Parks, and K. Floyd, Making friends in cyberspace. Journal of Communication, 46(1), p80-97, http://dx.doi.org/10.1111/j.1460-2466.1996.tb01462.x.

[23] T.J. Johnson, and B.K. Kaye, Choosing is believing? How web gratifications and reliance affect internet credibility among politically interested users. Atlantic Journal of Communication, 18(1), p1-21, 2010. http://dx.doi.org/10.1080/15456870903340431.

[24] J.D. Greer, Evaluating the credibility of online information: A test of source and advertising influence. Mass Communication and Society, 6(1), p11-28, 2003. http://dx.doi.org/10.1207/S15327825MCS0601_3.

[25] N.P. Nickerson, and G.D. Ellis, Traveler types and activation theory: A comparison of two models. Journal of Travel Research, 29(3), p517-527, 1991. http://dx.doi.org/10.1177/004728759102900304. 
[26] W.S. Roehl, and D.R. Fesenmaier, Risk perception and pleasure travel: An exploratory analysis. Journal of Travel Research, 30(4), p17-26, 1992. http://dx.doi.org/10.1177/004728759203000403.

[27] T.L. Turten, and M. Bosnjak, Understanding differences in Web usage: The role of need for cognition and five factor model of personality. Social Behavior and Personality, 29(4), p391-398, 2001. http://dx.doi.org/10.2224/sbp.2001.29.4.391.

[28] M. Ma, and R. Agarwal, Through a glass darkly: Information technology design, identity verification, and knowledge contribution in online communities. Information System Research, 18(1), p42-67, 2007. http://dx.doi.org/10.1287/isre.1070.0113.

[29] S.W. Sussman, and W.S. Seigal, Information influence in organizations: An integrated approach to knowledge adoption. Information System Research, 14(1), p47-65, 2003.

[30] W.B. Dodds, K.B. Monroe, and D. Grewal, Effect of price, brand, and store information on buyers' product evaluations. Journal of Marketing Research, 28(3), p35-51, 1991. http://www.jstor.org/stable/3172866.

[31] Y. Bart, V. Shankar, F. Sultan, and G.L. Urban, Are the drivers and role of online trust the same for all web sites and consumers? A large scale exploratory empirical study. Journal of Marketing, 69(4), p133-152, 2005. http://dx.doi.org/10.1509/jmkg.2005.69.4.133.

[32] M.D. West, Validating a scale for the measurement of credibility of credibility: A covariance structure modeling approach. Journalism Quarterly, 71(1), p90-98, 1994. http://dx.doi.org/10.1177/107769909407100115.

[33] M.R. Barrick, and M.K. Mount, The big five personality dimensions and job performance: A meta-analysis. Personnel Psychology, 44(1), p1-26, 1991. http://dx.doi.org/10.1111/j.1744-6570.1991.tb00688.x.

[34] J.F. Hair, R.E. Anderson, R.L. Tatham, and W.C. Black, Multivariate data analysis. London: Prentice Hall, 1998.

[35] A.F. Hayes, and J.K. Preacher, Asymptotic and resampling strategies for assessing and comparing indirect effects in multiple mediator models. Behavior Research Methods, 40(3), p879-891, 2008. http://dx.doi.org/10.3758/BRM.40.3.879.

[36] J.C. Nunnally, Psychometric Theory ( $2^{\text {nd }}$ edition). New York: McGraw-Hill, 1967. 
